\title{
Implementasi Data Mining Untuk Penyusunan Tata Letak Data Obat-Obatan Dengan Menggunakan Algoritma K- Harmonic Means Pada Apotek Inti Fada Sidamanik
}

\author{
${ }^{1}$ Yohanni Syahra, ${ }^{2}$ Rico Imanta Ginting, ${ }^{3}$ Milfa Yetri \\ 1,2,3 STMIK Triguna Dharma \\ A. H. Nasution No. 73 F Medan Sumatera Utara Indonesia \\ e-mail :1 yohanni.syahra@gmail.com, ${ }^{2}$ imantarico@gmail.com, ${ }^{3}$ airputih.girl@gmail.com
}

\begin{abstract}
Abstrack-Apotek Inti Fada Sidamanik is engaged in community service. The rapid development of technology, requires humans to apply in all fields in order to achieve technological progress. Including one of them in the pharmaceutical field. The high level of diversity of drugs requires people to be able to manage them more thoroughly so that their use is more easily classified. With the existence of a good management or medication list management, the information sought will be more easily obtained so that it can shorten the time used. The use of computers is very accurate and fast. Computerized data processing is very necessary to get information, which can be used to produce solutions to existing problems, such as drugs can be neatly arranged according to the shelf and dosage of each drug. The purpose of this research is to build a system of drug data management information at the Pharmacy Core Fada Sidamanik in order to facilitate and streamline information systems that are not well structured.
\end{abstract}

Keywords: Data Mining, K-Harmonic Means Algorithm, Arrangement of Drug Data Layout.

Abstrak-Apotek Inti Fada Sidamanik bergerak dalam bidang pelayanan masyarakat. Perkembangan teknologi yang semakin pesat, menuntut manusia untuk melakukan penerapan disegala bidang guna mencapai kemajuan teknologi. Termasuk salah satunya pada bidang farmasi. Tingginya tingkat keragaman obat-obatan menuntut orang-orang agar dapat mengelolanya lebih teliti sehingga dalam penggunaannya lebih mudah diklasifikasikan. Dengan adanya suatu manajemen atau pengelolaan daftar obat yang baik, maka informasi yang dicari akan lebih mudah diperoleh sehingga dapat mempersingkat waktu yang digunakan.Penggunaan komputer sangat akurat dan cepat. Pengolahan data secara komputerisasi sangat diperlukan untuk mendapatkan informasi, yang dapat digunakan untuk menghasilkan solusi-solusi dari masalah yang ada, seperti obat dapat tersusun rapi sesuai dengan raknya dan dosis masing-masing obat. Maksud dari penelitian ini adalah membangun sistem informasi pengelolaan data obat pada Apotek Inti Fada Sidamanik guna mempermudah dan mengefesiensikan sistem informasi yang belum tersusun dengan baik.

Kata Kunci: Data Mining, Algoritma K-Harmonic Means, Penyusunan Tata Letak Data Obat-Obatan.

\section{PENDAHULUAN}

Berbicara tentang Sistem Informatika Manajemen dalam bidang farmasi ada beberapa hal yang sangat berkaitan erat dengan itu. Sistem adalah suatu tahapan yang berhubungan dengan input, proses dan output. Sedangkan informasi berkaitan erat dengan data yang akan diolah menjadi informasi. Bagaimanakah kita menghubungkan antara sistem informasi dan farmasi.

Selain hal tersebut di atas, dalam pengolahan obat banyak ditemukan obat yang melebihi masa kadaluarsa. Hal ini disebabkan proses dokumentasi keluar masuknya obat masih dilakukan dengan pembukuan. Untuk memudahkan operasional gudang obat penelitian ini merancang suatu sistem informasi yang dapat membantu dalam mengoptimalkan aktivitas penjualan obat, agar tidak terdapat penjualan obat yang sudah kadaluarsa. Penggunaan komputer sangat akurat dan cepat.Pengolahan data secara komputerisasi sangat diperlukan untuk mendapatkan informasi, yang dapat digunakan untuk menghasilkan solusisolusi dari masalah yang ada, seperti obat dapat tersusun rapi sesuai dengan raknya dan dosis masing-masing obat.

Algoritma K-Harmonic Means merupakan pengembangan dari $\mathrm{K}$ Means yang memperbaiki kekurangan dari $\mathrm{K}$ Means dengan menggunakan fungsi objektif yang di dapatkan dengan cara meminimalisasi rata-rata harmonik dari jarak seluruh data dengan tiap centroid. Dari proses pengelompokan ini akan diperoleh masing-masing centroid untuk setiap kelompok data. Maka judul yang dapat diangkat dalam permasalahan diatas adalah "Implementasi Data Mining Untuk Penyusunan Tata Letak Data Obat-Obatan Dengan Menggunakan Algoritma K-Harmonic Means Pada Apotek Inti Fada Sidamanik ”.

19 | http://www.jurnal.umb.ac.id/index.php/JTIS 


\section{LANDASAN TEORI}

A. Pengenalan Data Mining

Data mining merupakan sebuah proses untuk menggali kumpulan data dan menemukan informasi di dalamnya ${ }^{1}$. Data mining merupakan proses pengekstrakan informasi dari jumlah kumpulan data yang besar dengan menggunakan algoritma dan tehnik gambar dari statistik, mesin pembelajaran dan sistem manajemen database. Penggalian data ini dilakukan pada sekumpulan data yang besar untuk menemukan pola atau hubungan yang ada dalam kumpulan data tersebut ${ }^{2}$. Hasil penemuan yang diperoleh setelah proses penggalian data ini, kemudian dapat digunakan untuk analisis yang lebih lanjut.

\section{B. Algoritma K-Harmonic Means}

K-Harmonic Means (KHM) pertama kali diperkenalkan oleh Zhang, Hsu, dan Dayal (1999) dari HP Laboratories Palo Alto yang kemudian dikembangkan oleh Hammerly dan Elkan pada tahun 2002. Tujuan pengembangan metode KHM adalah untuk menangani masalah utama dalam KMeans yang hasil clusteringnya sangat sensitif dengan inisialisasi data yang dijadikan sebagai centroid awal. Hasil yang sering berbeda (lokal optima) dari proses clusteringnya (pada set data yang sama) disebabkan oleh inisialisasi centroid yang berbeda.

Secara prinsip, KHM menggunakan jumlah semua titik data dari rata-rata harmonik kuadrat jarak dari titik data ke semua centroid sebagai fungsi objektifnya, seperti disajikan dalam persamaan (2.3). Persamaan (2.3) sebagai fungsi objektif KHM sangat berbeda terhadap K-Means yang menggunakan total varian data dalam cluster. Dalam KHM, $\mathrm{C}=\{c j \mid j=1, \ldots, \mathrm{K}\}$ adalah $\mathrm{K}$ centroid, dan $\mathrm{X}=\{x i \mid i=1, \ldots, \mathrm{N}\}$ adalah $\mathrm{N}$ data yang dicluster, fungsi objektif KHM diberikan oleh persamaan (2.3)

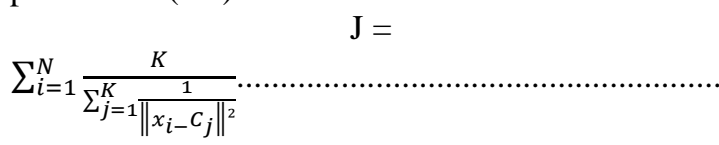

Dimana : $\mathbf{J}=$ fungsi objektif $\mathrm{KHM}$

$\mathrm{N}=$ data yang dicluster

$\mathrm{K}=$ centroid

$\mathrm{xi}=$ data ke-i

$\mathrm{cj}=$ centroid $\mathrm{ke}-\mathrm{j}$

Kuantitas didalam ruas kanan adalah rata-rata harmonik dari $\mathrm{K}$ jarak kuadrat,

$$
\left\{\left\|x_{i-} C_{j}\right\|^{2} \mid j=\right.
$$

Algoritma clustering dengan K-Harmonic Means sebagai berikut (Zhang, B. et al., 1999):

1. Tentukan Nilai K sebagai jumlah kelompok / cluster.
2. Inisialisasi posisi centroid awal dimana $\mathrm{C}=\{\mathrm{c} j$ $\mid j=1, \ldots, \mathrm{K}\}$ sebanyak $\mathrm{K}$ centroid secara acak dari data yang ada.

3. Hitung Jarak data terhadap masing-masing centroid. Misalnya menggunakan rumus jarak euclidean seperti persamaan berikut :

$$
d i, j=|\mathrm{x} i-\mathrm{c} j|_{2}=\sqrt[2]{\left(x_{i}\right.}-
$$

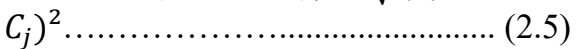

Dimana $\mathrm{X}=\{\mathrm{x} i \mid i=1 \ldots . \mathrm{N}\}, \mathrm{N}$ adalah jumlah data yang akan diklaster dengan metode KHM.

4. Cari jarak terdekat $\mathrm{d} i$, min dan masukkan $\mathrm{X}$ kedalam cluster sesuai dengan kelompok/centroid tersebut.

5. Cari centroid baru sebanyak $\mathrm{K}$ dengan persamaan KHM seperti berikut :

$$
m_{i, k}=\frac{\sum_{i=1}^{N} \frac{1}{d_{i, k^{3}\left(\sum_{j}^{K}=1 \frac{1}{d_{i, j^{2}}}\right)^{2}}} x_{i}}{\sum_{i=1}^{N} \frac{1}{d_{i, k^{3}\left(\sum_{j}^{K}=1 \frac{1}{d_{i, j^{2}}}\right)^{2}}}}
$$

Dimana : mi,k = centroid baru metode KHM

$\mathrm{N}=$ data yang dicluster

di,k $=$ jarak antara i ke $\mathrm{k}$

$\mathrm{di}, \mathrm{j}=$ jarak antara $\mathrm{i}$ ke $\mathrm{j}$

$\mathrm{xi}=$ data $\mathrm{ke}-\mathrm{i}$

Catatan $: \mathrm{d} \mathrm{i}, \min =0$ maka vektor $\mathrm{mk}$ diset menjadi 0 .

6. Lakukan langkah nomor 2 - 4 hingga posisi anggota cluster tidak berubah.

\section{Analisa Dan Perancangan}

1. Analisis Permasalahan

Pada bagian ini merupakan penjelasan hasil pengamatan terhadap kesesuaian penggunaan metode dengan permasalahan. Kesehatan merupakan hak asasi manusia dan sekaligus merupakan investasi untuk keberhasilan pembangunan Bangsa Indonesia. Oleh karena itu perlu dilakukan pembangunan kesehatan secara menyeluruh dan berkesinambungan, dengan tujuan guna meningkatkan kesadaran, kemauan dan kemampuan hidup sehat bagi setiap orang agar terwujud derajat kesehatan masyarakat yang setinggi-tingginya, salah satu caranya adalah dengan meningkatkan akses dan mutu pelayanan kesehatan. Saat ini kenyataanya sebagian besar Puskesmas di Indonesia belum melakukan kegiatan pelayanan farmasi seperti yang diharapkan, mengingat beberapa kendala antara lain kemampuan tenaga farmasi, terbatasnya pengetahuan manajemen Puskesmas akan fungsi farmasi obat, kebijakan manajemen institusi yang membawahi suatu Puskesmas, terbatasnya pengetahuan pihak-pihak terkait tentang pelayanan farmasi. Akibat kondisi ini maka pelayanan farmasi Puskesmas masih bersifat konvensional yang hanya berorientasi pada produk yaitu sebatas penyediaan 
dan pendistribusian. Salah satu metode data mining yang dapat digunakan dari analisa diatas adalah metode clustering, yang merupakan pengelompokkan item data ke dalam sejumlah kecil grup sedemikian sehingga masing-masing grup mempunyai sesuatu persamaan yang esensial.

\section{Persiapan Data (Data Preparation)}

Tahap ini merupakan tahapan untuk mempersiapkan data yang diperlukan untuk proses data mining. Tujuannya adalah agar data yang digunakan benar-benar sesuai dengan permasalahan yang akan dipecahkan, dapat dijamin kebenarannya, dan dalam format yang sesuai atau tepat.Data yang diambil adalah data obat-obatan pada Apotek Inti Fada Sidamanik.

Tabel 1 Tabel Sampel Data Obat-obatan

\begin{tabular}{|l|c|c|}
\hline \multicolumn{1}{|c|}{ Nama Obat } & Satuan & $\begin{array}{c}\text { Harga Non-Rsp } \\
\text { (RP) }\end{array}$ \\
\hline Abbocath 18 & Pcs & 14,950 \\
\hline Abbocath 20 & Pcs & 14,950 \\
\hline Absolute & Pcs & 14,400 \\
\hline Aceton $60 \mathrm{ml}$ & Botol & 6,750 \\
\hline Acifar cr 5 gr & Tube & 6,400 \\
\hline
\end{tabular}

3. Algoritma Sistem

Perhitungan KHM menggunakan data set yang terdiri dari 27 data yang memiliki 2 atribut yaitu satuan dan harga. Berikut tabel data tersebut

Tabel 2 Tabel Data Obat-Obatan

\begin{tabular}{|c|c|c|c|}
\hline No. & Data & Satuan & Harga \\
\hline A. & Obat FLU & & \\
\hline 1 & -Actifed syrup & 2 & 2 \\
\hline 2 & -Bodrex Flu dan Batuk & 2 & 1 \\
\hline 3 & -Anadex Tablet & 5 & 2 \\
\hline B. & $\begin{array}{l}\text { Obat Batuk Ekspetotan ( } \\
\text { Berdahak) }\end{array}$ & & \\
\hline 4 & -Orciprenaline(tablet) & 5 & 3 \\
\hline 5 & -Terbutaline(strip) & 4 & 2 \\
\hline 6 & -Dexamethason(tablet) & 5 & 1 \\
\hline C. & Obat asma & & \\
\hline 7 & -Teofilin & 4 & 3 \\
\hline 8 & -Natrium kromolat & 8 & 4 \\
\hline 9 & -Kortikosteroid & 5 & 5 \\
\hline D. & Obat Amandel & & \\
\hline 10 & -Paracetamol syrup & 2 & 1 \\
\hline 11 & $\begin{array}{l}\text {-Sanjin Watermelon } \quad \text { Frost } \\
\text { Insufflations(botol) }\end{array}$ & 2 & 5 \\
\hline 12 & -Ibuprofen tablet & 5 & 1 \\
\hline E. & Obat Diabetes & & \\
\hline 13 & -Aldovas Tab & 5 & 6 \\
\hline 14 & -Actos 30mg tab & 5 & 5 \\
\hline 15 & -Galvus 50mg tab & 5 & 4 \\
\hline F. & Obat Anemia & & \\
\hline 16 & -Tonikum Bayer & 2 & 3 \\
\hline 17 & -Sangobion (kapsul) & 8 & 1 \\
\hline 18 & -Sakatonik Liver(botol) & 2 & 3 \\
\hline G. & Obat Liver & & \\
\hline 19 & -Liver Prime Capsul kapsul & 8 & 10 \\
\hline 20 & -Hepamax Cap Botol & 2 & 10 \\
\hline 21 & -Hepatosol Cokl 185g & 1 & 1 \\
\hline H. & Obat Sakit Gigi & & \\
\hline 22 & -Cataflam Tablet $25 \mathrm{mg}$ & 5 & 1 \\
\hline 23 & -Cataflam Drops Botol & 2 & 3 \\
\hline 24 & -Asam Metamanat Berno tab & 5 & 1 \\
\hline
\end{tabular}

\begin{tabular}{|l|l|l|l|}
\hline I. & Obat cacing & 5 & 1 \\
25 & -Combantrin tab & 2 & 1 \\
26 & -Combantrin syrup & 5 & 2 \\
27 & -Vermox tab & 5 \\
\hline
\end{tabular}

Langkah pertama, melakukan perhitungan menggunakan metode K-Harmonic Means (KHM) adalah menentukan nilai $\mathrm{K}$ sebagai jumlah kelompok/cluster. Nilai K pada contoh perhitungan ini telah ditentukan sebanyak 2.

\section{Iterasi 1}

Langkah kedua, melakukan inisialisasi posisi centroid awal dimana $\mathrm{C}=\{\mathrm{c} j \mid j=1, \ldots, \mathrm{K}\}$ sebanyak $\mathrm{K}$ centroid secara acak dari data yang ada, yaitu :

Tabel 3.3 Centroid Awal

\begin{tabular}{|c|c|c|c|}
\hline No & Data & Satuan & Harga \\
\hline 2 & Bodrex flu dan batuk & 2 & 1 \\
\hline 13 & Aldovas tab & 5 & 6 \\
\hline
\end{tabular}

Ketiga menghitung jarak data terhadap masing masing centroid menggunakan rumus jarak euclidean seperti persamaan (2.5)

$$
\begin{array}{ll}
d_{1,1}=\sqrt{(2-2)^{2}+(2-1)^{2}=} 1 & d_{1,2}= \\
\sqrt{(2-5)^{2}+(2-6)^{2}=} 5,00 & \\
d_{2,1}=\sqrt{(2-2)^{2}+(1-1)^{2}=} 0 & d_{2,2}= \\
\sqrt{(2-5)^{2}+(1-6)^{2}}=5,83 & \\
d_{3,1}=\sqrt{(5-2)^{2}+(2-1)^{2}}=3,16 & d_{3,2}= \\
\sqrt{(5-5)^{2}+(2-6)^{2}}=4,00 &
\end{array}
$$

Lakukan perhitungan yang sama hingga $d_{27,1}$ dan $d_{27,2}$

Langkah keempat, mencari jarak terdekat $d_{i, \min }$ dan masukkan X kedalam cluster sesuai dengan kelompok / centroid tersebut.

Tabel 4 Hasil Perhitungan Jarak dan Pengelompokan Data

\begin{tabular}{|c|l|c|c|c|c|c|c|}
\hline No & Data & $\begin{array}{c}\text { Sa } \\
\text { tu } \\
\text { an }\end{array}$ & $\begin{array}{c}\mathbf{H} \\
\mathbf{a r} \\
\text { ga }\end{array}$ & $\begin{array}{c}\text { Jara } \\
\mathbf{k} 1\end{array}$ & $\begin{array}{c}\text { Jara } \\
\mathbf{k} \\
\mathbf{C 2}\end{array}$ & $\begin{array}{c}\text { Jara } \\
\mathbf{k} \\
\text { Min }\end{array}$ & $\begin{array}{c}\text { Clus } \\
\text { ter }\end{array}$ \\
\hline 1 & $\begin{array}{l}\text { Actifed } \\
\text { syrup }\end{array}$ & 2 & 2 & 1,00 & 5,00 & 1,00 & 1 \\
\hline 2 & $\begin{array}{l}\text { Bodrex } \\
\text { Flu dan } \\
\text { Batuk }\end{array}$ & 2 & 1 & 0,00 & 5,83 & 0,00 & 1 \\
\hline 3 & $\begin{array}{l}\text { Anadex } \\
\text { Tablet }\end{array}$ & 5 & 2 & 3,16 & 4,00 & 3,16 & 1 \\
\hline 4 & $\begin{array}{l}\text { Orcipre } \\
\text { naline(ta } \\
\text { blet) }\end{array}$ & 5 & 3 & 3,61 & 3,00 & 3,00 & 2 \\
\hline 5 & $\begin{array}{l}\text { erbutali } \\
\text { ne(strip) }\end{array}$ & 4 & 2 & 2,24 & 4,12 & 2,24 & 1 \\
\hline
\end{tabular}

21 | http://www.jurnal.umb.ac.id/index.php/JTIS 


\begin{tabular}{|c|c|c|c|c|c|c|c|}
\hline 6 & $\begin{array}{l}\text { Dexame } \\
\text { thason(t } \\
\text { ablet) }\end{array}$ & 5 & 1 & 3,00 & 5,00 & 3,00 & 1 \\
\hline 7 & Teofilin & 4 & 3 & 2,83 & 3,16 & 2,83 & 1 \\
\hline 8 & $\begin{array}{l}\text { Natrium } \\
\text { kromola } \\
\mathrm{t}\end{array}$ & 8 & 4 & 6,71 & 3,61 & 3,61 & 2 \\
\hline 9 & $\begin{array}{l}\text { Kortikos } \\
\text { teroid }\end{array}$ & 5 & 5 & 5,00 & 1,00 & 1,00 & 2 \\
\hline 10 & $\begin{array}{l}\text { Paraceta } \\
\text { mol } \\
\text { syrup }\end{array}$ & 2 & 1 & 0,00 & 5,83 & 0,00 & 1 \\
\hline 11 & $\begin{array}{l}\text { Sanjin } \\
\text { Waterm } \\
\text { elon } \\
\text { Frost } \\
\text { Insufflat } \\
\text { ions(bot } \\
\text { ol) }\end{array}$ & 2 & 5 & 4,00 & 3,16 & 3,16 & 2 \\
\hline 12 & $\begin{array}{l}\text { Ibuprofe } \\
\text { n tablet }\end{array}$ & 5 & 1 & 3,00 & 5,00 & 3,00 & 1 \\
\hline 13 & $\begin{array}{l}\text { Aldovas } \\
\text { Tab }\end{array}$ & 5 & 6 & 5,83 & 0,00 & 0,00 & 2 \\
\hline 14 & $\begin{array}{l}\text { Actos } \\
30 \mathrm{mg} \\
\text { tab }\end{array}$ & 5 & 5 & 5,00 & 1,00 & 1,00 & 2 \\
\hline 15 & $\begin{array}{l}\text { Galvus } \\
50 \mathrm{mg} \\
\text { tab }\end{array}$ & 5 & 4 & 4,24 & 2,00 & 2,00 & 2 \\
\hline 16 & $\begin{array}{l}\text { Toniku } \\
\text { m Bayer }\end{array}$ & 2 & 3 & 2,00 & 4,24 & 2,00 & 1 \\
\hline 17 & $\begin{array}{l}\text { Sangobi } \\
\text { on } \\
\text { (kapsul) }\end{array}$ & 8 & 1 & 6,00 & 5,83 & 5,83 & 2 \\
\hline 18 & $\begin{array}{l}\text { Sakatoni } \\
\mathrm{k} \\
\text { Liver(bo } \\
\text { tol) }\end{array}$ & 2 & 3 & 2,00 & 4,24 & 2,00 & 1 \\
\hline 19 & $\begin{array}{l}\text { Liver } \\
\text { Prime } \\
\text { Capsul } \\
\text { kapsul } \\
\end{array}$ & 8 & 10 & $\begin{array}{c}10,8 \\
2\end{array}$ & 5,00 & 5,00 & 2 \\
\hline 20 & $\begin{array}{l}\text { Hepama } \\
\text { x Cap } \\
\text { Botol }\end{array}$ & 2 & 10 & 9,00 & 5,00 & 5,00 & 2 \\
\hline 21 & $\begin{array}{l}\text { Hepatos } \\
\text { ol Cokl }\end{array}$ & 1 & 1 & 1,00 & 6,40 & 1,00 & 1 \\
\hline 22 & $\begin{array}{l}\text { Catafla } \\
\mathrm{m} \\
\text { Tablet } \\
25 \mathrm{mg}\end{array}$ & 5 & 1 & 3,00 & 5,00 & 3,00 & 1 \\
\hline 23 & $\begin{array}{l}\text { Catafla } \\
\text { m Drops } \\
\text { Botol }\end{array}$ & 2 & 3 & 2,00 & 4,24 & 2,00 & 1 \\
\hline 24 & $\begin{array}{l}\text { Asam } \\
\text { Metama } \\
\text { nat } \\
\text { Berno } \\
\text { tab }\end{array}$ & 5 & 1 & 3,00 & 5,00 & 3,00 & 1 \\
\hline 25 & $\begin{array}{l}\text { Comban } \\
\text { trin tab }\end{array}$ & 5 & 1 & 3,00 & 5,00 & 3,00 & 1 \\
\hline 26 & $\begin{array}{l}\text { Comban } \\
\text { trin } \\
\text { syrup }\end{array}$ & 2 & 1 & 0,00 & 5,83 & 0,00 & 1 \\
\hline 27 & $\begin{array}{l}\text { Vermox } \\
\text { tab }\end{array}$ & 5 & 2 & 3,16 & 4,00 & 3,16 & 1 \\
\hline
\end{tabular}

Kelima mencari centroid baru sebanyak K sesuai dengan persamaan (2.6):

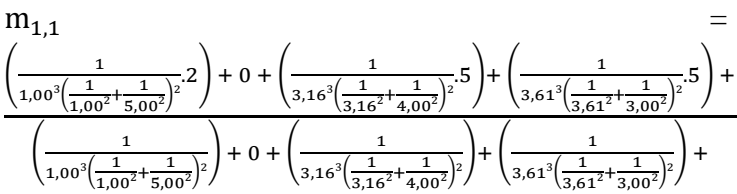

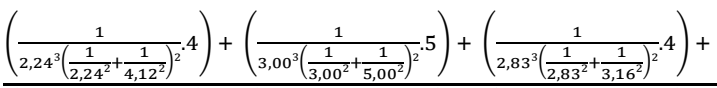

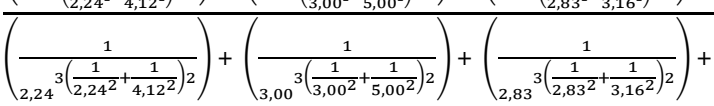

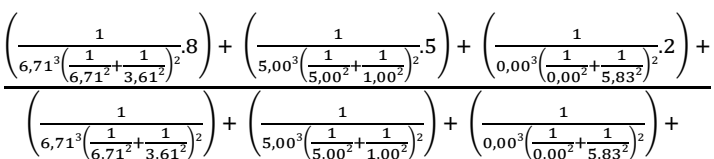

$\frac{\left(\frac{1}{4,00^{3}\left(\frac{1}{4,00^{2}}+\frac{1}{3,16^{2}}\right)^{2}} \cdot 2\right)+\left(\frac{1}{3,00^{3}\left(\frac{1}{3,00^{2}}+\frac{1}{5,00^{2}}\right)^{2}} \cdot 5\right)+0+\left(\frac{1}{5,00^{3}\left(\frac{1}{5,00^{2}}+\frac{1}{1,00^{2}}\right)^{2}} \cdot 5\right)+}{\left(\frac{1}{4,00^{3}\left(\frac{1}{4,00^{2}}+\frac{1}{3,16^{2}}\right)^{2}}\right)+\left(\frac{1}{3,00^{3}\left(\frac{1}{3,00^{2}}+\frac{1}{5,00^{2}}\right)^{2}}\right)+0+\left(\frac{1}{5,00^{3}\left(\frac{1}{5,00^{2}}+\frac{1}{1,00^{2}}\right)^{2}}\right)+}$

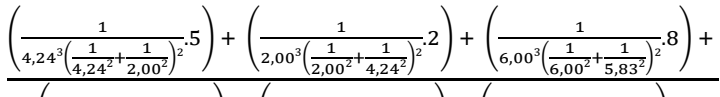
$\left(\frac{1}{4,24^{3}\left(\frac{1}{4,24^{2}}+\frac{1}{2,00^{2}}\right)^{2}}\right)+\left(\frac{1}{2,00^{3}\left(\frac{1}{2,00^{2}}+\frac{1}{4,24^{2}}\right)^{2}}\right)+\left(\frac{1}{6,00^{3}\left(\frac{1}{6,00^{2}}+\frac{1}{5,83^{2}}\right)^{2}}\right)+$

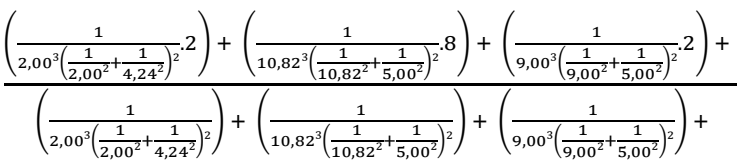

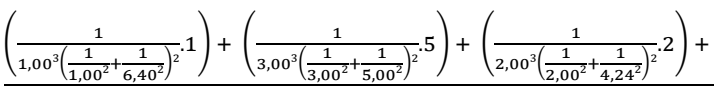

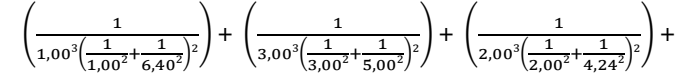

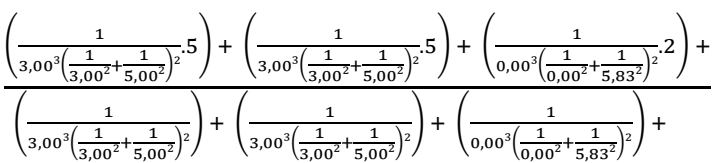

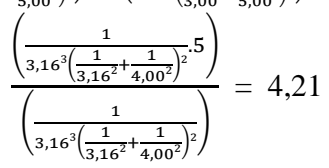

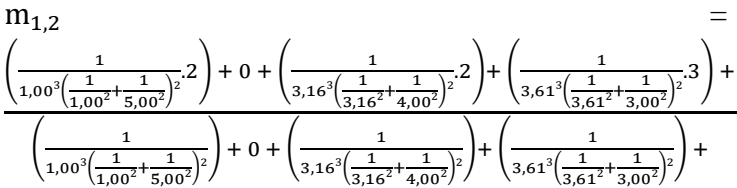

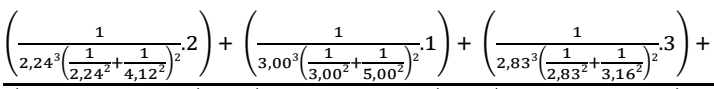
$\left(\frac{1}{2,24^{3}\left(\frac{1}{2,24^{2}}+\frac{1}{4,12^{2}}\right)^{2}}\right)+\left(\frac{1}{3,00^{3\left(\frac{1}{3,00^{2}}+\frac{1}{5,00^{2}}\right)^{2}}}\right)+\left(\frac{1}{2,83^{3}\left(\frac{1}{2,83^{2}}+\frac{1}{3,16^{2}}\right)^{2}}\right)+$

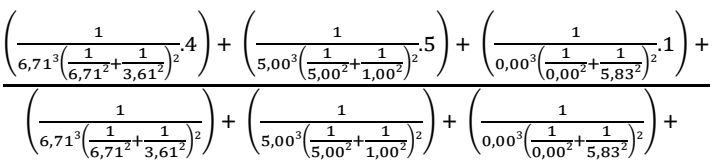

22 | http://www.jurnal.umb.ac.id/index.php/JTIS 


$$
\begin{aligned}
& \frac{\left(\frac{1}{4,00^{3}\left(\frac{1}{4,00^{2}}+\frac{1}{3,16^{2}}\right)^{2}} \cdot 5\right)+\left(\frac{1}{3,00^{3}\left(\frac{1}{3,00^{2}}+\frac{1}{5,00^{2}}\right)^{2}} \cdot 1\right)+0+\left(\frac{1}{5,00^{3}\left(\frac{1}{5,00^{2}}+\frac{1}{1,00^{2}}\right)^{2}} \cdot 5\right)+}{\left(\frac{1}{4,00^{3}\left(\frac{1}{4,00^{2}}+\frac{1}{3,16^{2}}\right)^{2}}\right)+\left(\frac{1}{3,00^{3}\left(\frac{1}{3,00^{2}}+\frac{1}{5,00^{2}}\right)^{2}}\right)+0+\left(\frac{1}{5,00^{3}\left(\frac{1}{5,00^{2}}+\frac{1}{1,00^{2}}\right)^{2}}\right)+}
\end{aligned}
$$

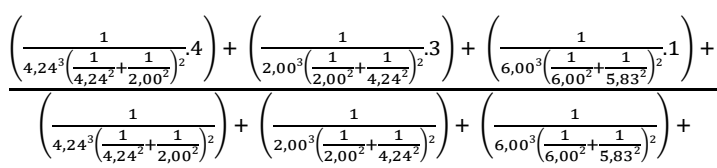

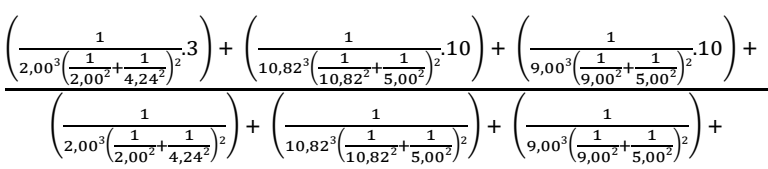

$$
\begin{aligned}
& \frac{\left(\frac{1}{1,00^{3}\left(\frac{1}{1,00^{2}}+\frac{1}{6,40^{2}}\right)^{2}} \cdot 1\right)+\left(\frac{1}{3,00^{3}\left(\frac{1}{3,00^{2}}+\frac{1}{5,00^{2}}\right)^{2}} \cdot 1\right)+\left(\frac{1}{2,00^{3}\left(\frac{1}{2,00^{2}}+\frac{1}{4,24^{2}}\right)^{2}} \cdot 3\right)+}{\left(\frac{1}{1,00^{3}\left(\frac{1}{1,00^{2}}+\frac{1}{6,40^{2}}\right)}\right)+\left(\frac{1}{3,00^{3}\left(\frac{1}{3,00^{2}}+\frac{1}{5,00^{2}}\right)^{2}}\right)+\left(\frac{1}{2,00^{3}\left(\frac{1}{2,00^{2}}+\frac{1}{4,24^{2}}\right)^{2}}\right)+}
\end{aligned}
$$

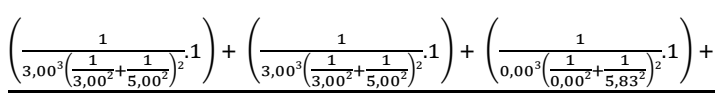

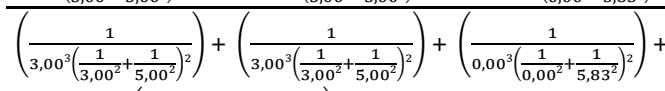

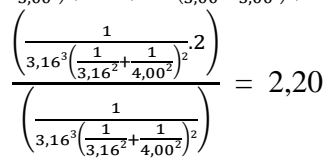

$\mathrm{m}_{2,1}$

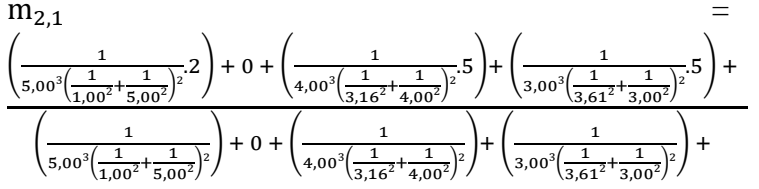

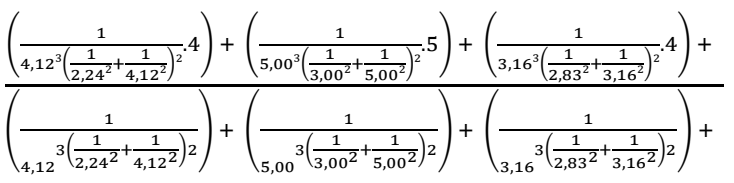

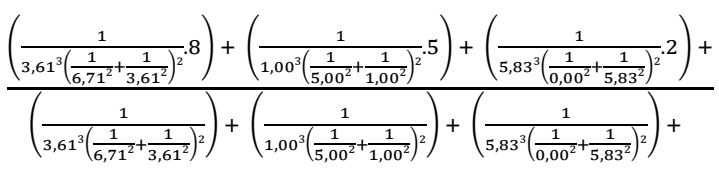

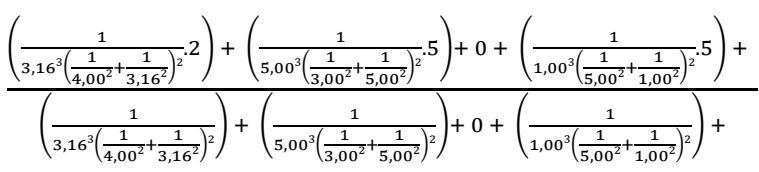

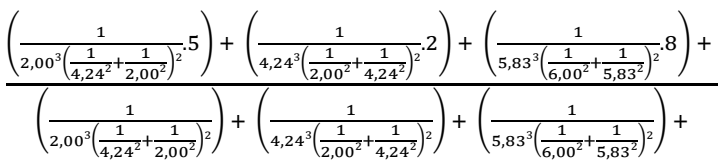

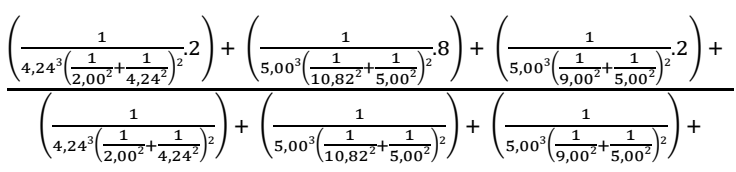

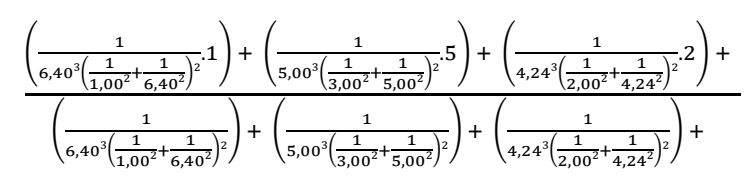
$\frac{\left(\frac{1}{5,00^{3}\left(\frac{1}{3,00^{2}}+\frac{1}{5,00^{2}}\right)^{2}} \cdot 5\right)+\left(\frac{1}{5,00^{3}\left(\frac{1}{3,00^{2}}+\frac{1}{5,00^{2}}\right)^{2}} \cdot 5\right)+\left(\frac{1}{5,83^{3}\left(\frac{1}{0,00^{2}}+\frac{1}{\left.5,83^{2}\right)^{2}} \cdot 2\right)+}\right.}{\left(\frac{1}{5,00^{3}\left(\frac{1}{3,00^{2}}+\frac{1}{5,00^{2}}\right)^{2}}\right)+\left(\frac{1}{5,00^{3}\left(\frac{1}{3,00^{2}}+\frac{1}{5,00^{2}}\right)^{2}}\right)+\left(\frac{1}{5,83^{3}\left(\frac{1}{0,00^{2}}+\frac{1}{5,83^{2}}\right)^{2}}\right)+}$

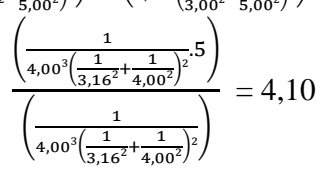

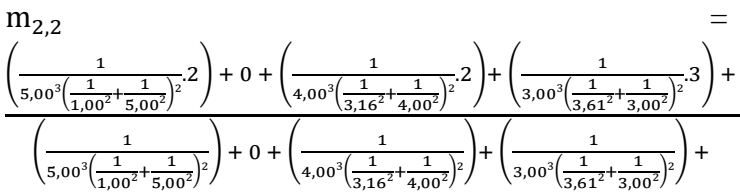

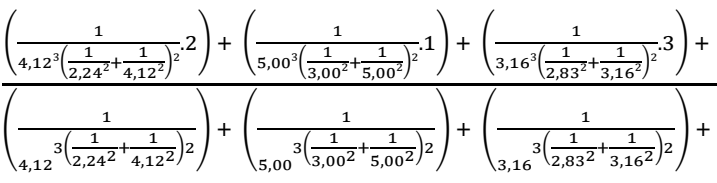

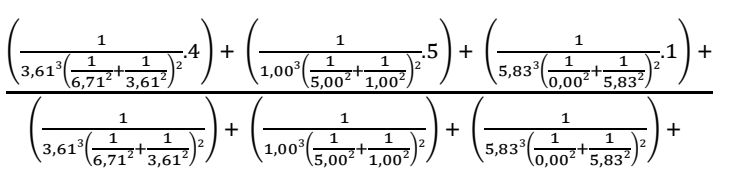

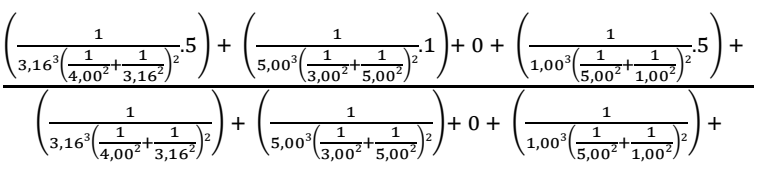

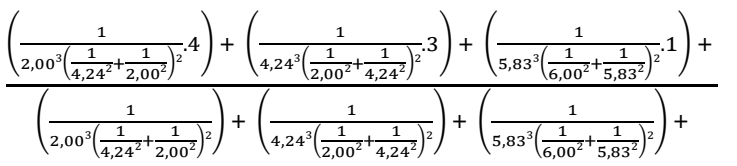
$\frac{\left(\frac{1}{4,24^{3}\left(\frac{1}{2,00^{2}}+\frac{1}{4,24^{2}}\right)^{2}} \cdot 3\right)+\left(\frac{1}{5,00^{3}\left(\frac{1}{10,82^{2}}+\frac{1}{5,00^{2}}\right)^{2}} \cdot 10\right)+\left(\frac{1}{5,00^{3}\left(\frac{1}{9,00^{2}}+\frac{1}{5,00^{2}}\right)^{2}} \cdot 10\right)+}{\left(\frac{1}{4,24^{3}\left(\frac{1}{2,00^{2}}+\frac{1}{4,24^{2}}\right)^{2}}\right)+\left(\frac{1}{5,00^{3}\left(\frac{1}{10,82^{2}}+\frac{1}{5,00^{2}}\right)^{2}}\right)+\left(\frac{1}{5,00^{3}\left(\frac{1}{9,00^{2}}+\frac{1}{5,00^{2}}\right)^{2}}\right)+}$

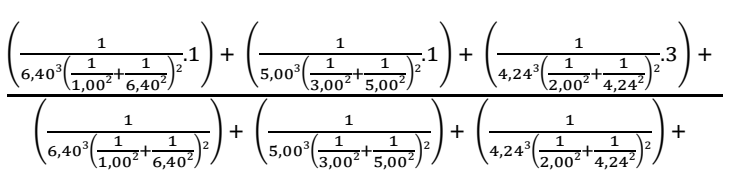
$\frac{\left(\frac{1}{5,00^{3}\left(\frac{1}{3,00^{2}}+\frac{1}{5,00^{2}}\right)^{2}} \cdot 1\right)+\left(\frac{1}{5,00^{3}\left(\frac{1}{3,00^{2}}+\frac{1}{5,00^{2}}\right)^{2}} \cdot 1\right)+\left(\frac{1}{5,83^{3}\left(\frac{1}{0,00^{2}}+\frac{1}{5,83^{2}}\right)^{2}} \cdot 1\right)+}{\left(\frac{1}{5,00^{3}\left(\frac{1}{3,00^{2}}+\frac{1}{5,00^{2}}\right)^{2}}\right)+\left(\frac{1}{5,00^{3}\left(\frac{1}{3,00^{2}}+\frac{1}{5,00^{2}}\right)^{2}}\right)+\left(\frac{1}{5,83^{3}\left(\frac{1}{0,00^{2}}+\frac{1}{5,83^{2}}\right)^{2}}\right)+}$

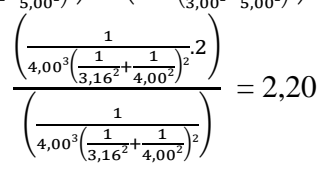

\section{Tabel 3.10 Centroid Baru}

\begin{tabular}{|l|l|l|}
\hline No. & Satuan & Harga \\
\hline
\end{tabular}




\begin{tabular}{|l|l|l|}
\hline 1 & 4,21 & 2,20 \\
\hline 2 & 4,10 & 2,20 \\
\hline
\end{tabular}

Lakukan langkah nomor 2 - 4 hingga posisi anggota cluster tidak berubah. Menghitung jarak data terhadap centroid baru menggunakan rumus jarak eucllidean seperti persamaan (2.5)

\section{Penetapan Kesimpulan}

Dari hasil perhitungan, didapatkan hasil :

a. Data 3,4,6,8,9,12,13,14,15,17,19,22,24,25,27 termasuk cluster/kelompok 1

b. Data $1,2,5,7,10,11,16,18,20,21,23,26$ termasuk cluster/kelompok 2

c. Cluster tetap berhasil ditemukan pada iterasi ke-3

Pengujian dialakukan pada 27 data acak yang memiliki 2 fitur seperti pada tabel 2.1, kemudian data - data tersebut di clustering menggunakan metode $K H M$ dengan nilai $\mathrm{k}=2$. Berdasarkan hasil pengujian dapat disimpulkan bahwa anggota clustering metode KHM tingkat konsistensi yang sangat baik yaitu $92 \%$.

\section{IMPLEMENTASI DAN PENGUJIAN}

\section{A. Kebutuhan Sistem}

Adapun kebutuhan sistem dalam penulisan laporan skripsi ini antara lain sebagai berikut :

1. Perangkat Keras (Hardware)

2. Perangkat Lunak (Software)

3. Manusia atau Pemakai (Brainware)

B. Implementasi Sistem

Implementasi interface merupakan hasil implementasi perancangan form kedalam bahasa pemograman Visual. Berikut hasil implementasi "Implementasi Data Mining Untuk Penyusunan Tata Letak Data Obat-Obatan Dengan Menggunakan Algoritma K-Harmonic Means Pada Apotek Inti Fada Sidamanik".

\section{Form Menu Utama}

Form menu utama adalah form kedua yang ditampilkan setelah user berhasil melakukan login. Form ini terdiri dari Submenu data yang terdiri dari form data obat, dan form jenis obat, submenu proses perhitungan dan form hasil iterasi, form lap data hasil perhitungan dan submenu keluar untuk keluar dari aplikasi. Adapun tampilan dari form utama adalah seperti terlihat pada gambar berikut:

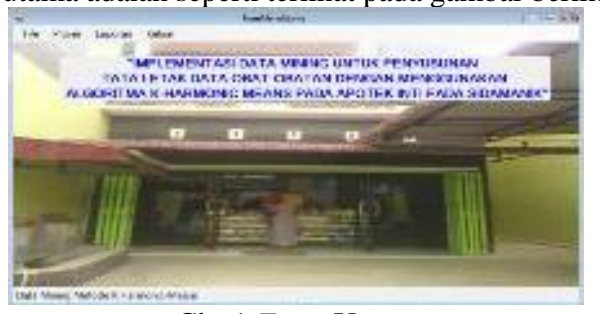

Gbr 1 Form Utama

\section{a. FormInput Data Obat}

Form data Obat adalah form yang berguna untuk menyimpan, mengubah dan menghapus data obat langsung ke database. Adapun tampilan keluaran dari form data obat adalah sebagai berikut :

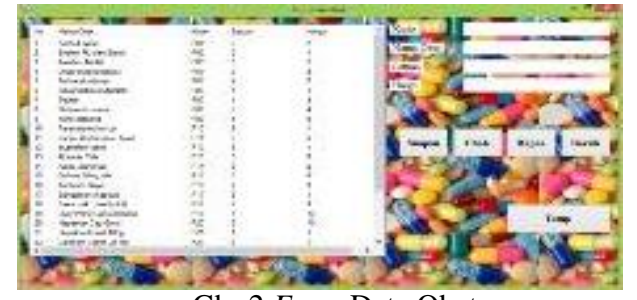

Gbr 2 Form Data Obat

b. Form Nillai Centroid

Form nilai centroid adalah form yang berguna untuk menyimpan, mengubah dan menghapus data Nilai centroid yang ditelah ditetapkan langsung ke database. Adapun tampilan keluaran dari form Nilai centroid adalah sebagai berikut :

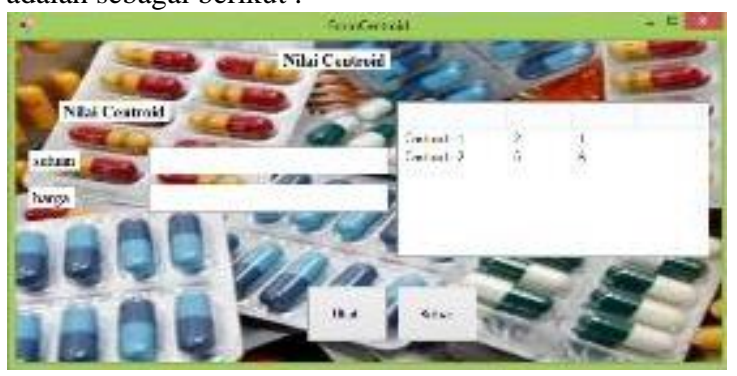

Gambar 3 Form Nilai Centroid

\section{Form Proses Perhitungan K-Harmonic Means}

Form prosesperhitungan K-Harmonic Means adalah form yang berguna untuk melakukan proses perhitungan pada Data Mining menggunakan Algoritma K-Harmonic Means setelah data obat-obatan dan data nilai centroid diinput oleh User dan menyimpan data hasil perhitungan langsung ke database. Adapun tampilan keluaran dari form proses perhitungan K-Harmonic Means adalah sebagai berikut :

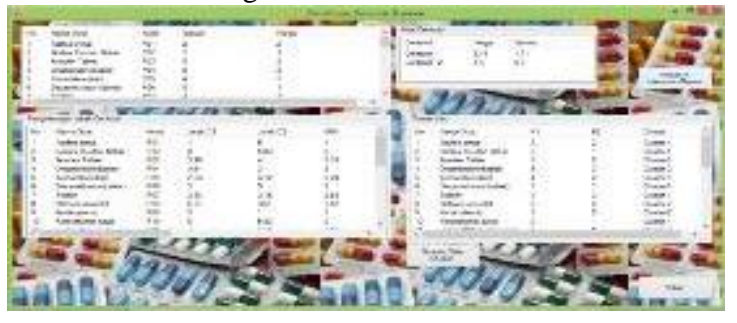

Gambar 4.4 Form Proses perhitungan K-Harmonic Means

\section{Form Laporan}

Form laporan adalah form yang berguna untuk menampilkan data hasil cluster yang dilakukan data mining setelah melewati proses perhitungan. Laporan ini nantinya akan digunakan sebagai bahan. Adapun tampilan keluaran dari form laporanadalah sebagai berikut : 


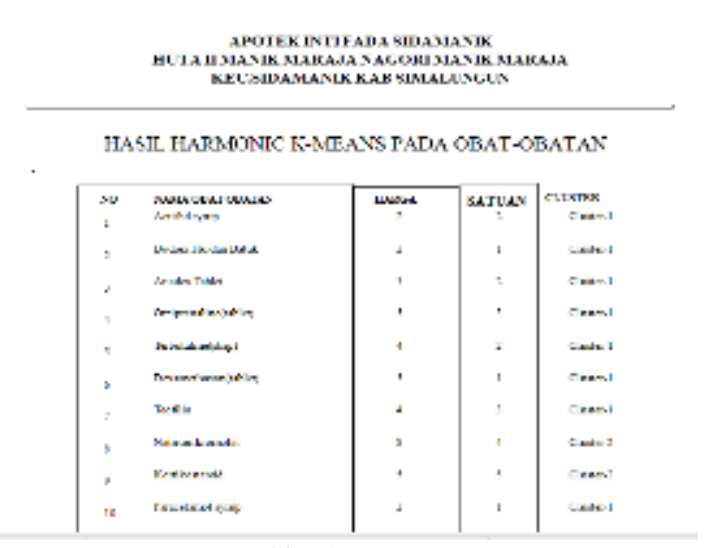

Gbr 5 Form Laporan

\section{KESIMPULAN DAN SARAN}

Perancangan aplikasi implementasi data mining untuk penyusunan tata letak data obat-obatan dengan menggunakan algoritma K-Harmonic Means pada apotek Inti Fada Sidamanik. Dapat diambil beberapa kesimpulan dan saran diantaranya adalah :

1. Algoritma K-Harmonic Means yang digunakan untuk penyusunan tata letak data obat-obatan pada Apotek Inti Fada Sidamanik telah berhasil diterapkan pada Aplikasi yang dibangun.

2. Aplikasi Data Mining dengan Algoritma KHarmonic Means membantu Apotek Inti Fada Sidamaik memberikan informasi yang cepat dan akurat.

3. Bagi pembacayang bersedia dan mampu menyempurnakan aplikasi ini hendaknya dilakukan perbaikan pada sistem dari segi tampilan-tampilan form, seperti pemberian animasi atau lainnya. Agar user tidak merasa jenuh jika menggunakan sistem.

4. Bagi pembaca yang bersedia dan mampu untuk menyempurnakan aplikasi ini hendaknya dilakukan pengembangan dengan cara penambahan menumenu agar sistem terkesan lebih lengkap dan handal.

\section{Referensi}

[1] Eko Prasetyo 2014. Data Mining-Mengolah Data Menjadi Informasi Menggunakan Matlab. Yogyakarta: Andi.

[2] Kusrini, \& Lutfi Taufik Emha 2011. Data Mining, Yogyakarta: Andi.

[3] Rosa, A S., \& Shalahuddin, M. 2016. Rekayasa Perangkat Lunak Terstruktur dan Berorientasi Objek. Bandung: Informatika Bandung.

[4] Hendrayudi. 2011. Dasar-Dasar Pemrograman Microsoft Visual Basic 2008. Bandung: PT. Sarana Tutorial Nurani Sejahtera.

[5] Made Widiartha. 2011. Studi Komparasi Metode Klasterisaasi Data K-Means dan K-Harmonic Means. Jurnal Ilmu Komputer Vol.4 - No 1- April 2011.

[6] Lee Christopher. 2014. Buku Pintar Visual Basic 2010. Jakarta: PT Elex Media Komputindo. 